\title{
Combined Chemotherapy with Mitomycin C, Folinic Acid, and 5-Fluorouracil (MiFoFU) as Salvage Treatment for Patients with Liver Metastases from Breast Cancer - a Retrospective Analysis
}

\author{
Michael H.R. Eichbaum ${ }^{\mathrm{a}} \quad$ Anne-Sybil Gast ${ }^{\mathrm{a}} \quad$ Thomas Bruckner $^{\mathrm{b}} \quad$ Andreas Schneeweiss $^{\mathrm{a}}$ \\ Christof Sohna \\ a Department of Gynecology and Obstetrics, \\ ${ }^{b}$ Department of Medical Biometry, University of Heidelberg Medical School, Germany
}

\section{Key Words}

Metastatic breast cancer - Liver metastases .

Mitomycin · 5-Fluorouracil · Folinic acid

\section{Summary}

Background: The aim of this study was to analyze the activity and tolerability of a combined chemotherapy with mitomycin C, folinic acid, and 5-fluorouracil (MiFoFU) in patients with hepatic metastases from breast cancer, and in particular in patients with impaired liver function. Patients and Methods: We retrospectively studied the charts of 44 patients who were treated with a MiFoFU combination therapy because of progressive metastatic breast cancer. Predominant site of metastases was the liver. Primary endpoints were response and time to progression (TTP); secondary endpoints were overall survival (OS) and tolerability. Results: Median age prior to treatment was 59 years. A median of 6 treatment cycles were administered per patient. Clinical benefit rate amounted to $64 \%$. A mean TTP of 9 months and a mean OS of 14 months were found. Main clinical signs of nonhematological toxicity were stomatitis, nausea, and diarrhea. Grade III/IV hematotoxicity was seen in only 9 patients. 16 patients showed clinical signs of liver dysfunction. A clinical benefit could be achieved in 8 of these patients. Conclusions: MiFoFU combination chemotherapy is a well-tolerated treatment alternative in the palliative therapy of patients with liver metastases from breast cancer. Particularly in patients with hepatic dysfunction, this regimen seems to represent a helpful treatment option.

\section{Schlüsselwörter \\ Metastasiertes Mammakarzinom - Lebermetastasen . Mitomycin · 5-Fluorouracil · Folinat}

\section{Zusammenfassung}

Hintergrund: Ziel dieser Studie war es, die Aktivität und Verträglichkeit einer Kombinationschemotherapie bestehend aus Mitomycin C, Folinat und 5-Fluorouracil (MiFoFU) in der Behandlung von Patientinnen mit Lebermetastasen eines Mammakarzinoms zu evaluieren. Insbesondere Patientinnen mit eingeschränkter Leberfunktion wurden untersucht. Patientinnen und Methoden: Wir analysierten retrospektiv die Krankenakten von $44 \mathrm{~Pa}$ tientinnen, die aufgrund eines progredienten metastasierten Mammakarzinoms mit einer MiFoFU-Kombinationschemotherapie behandelt wurden. Hauptmetastasenlokalisation war die Leber. Primäre Studienziele waren Therapieansprechen und Zeit zur Progression, sekundäre Studienziele waren Gesamtüberleben und Veträglichkeit. Ergebnisse: Das mediane Alter vor Behandlunsgbeginn betrug 59 Jahre. Im Median wurden 6 Therapiezyklen pro Patientin verabreicht. Die Clinical-benefitRate lag bei $64 \%$. Eine mittlere Zeit zur Progression von 9 Monaten und ein mittleres Gesamtüberleben von 14 Monaten wurden ermittelt. Wichtigste nichthämatologische Toxizitäten waren Stomatitis, Übelkeit und Diarrhoe. Grad III/IV-Hämatotoxizität wurde nur bei 9 Patientinnen beobachtet. 16 Patientinnen zeigten klinische Anzeichen einer Leberdysfunktion. Bei 8 dieser Patientinnen konnte ein klinischer Benefit erreicht werden. Schlussfolgerungen: Eine MiFoFU-Kombinationchemotherapie ist eine gut verträgliche Alternative in der palliativen Therapie von Patientinnen mit Lebermetastasen eines Mammakarzinoms. Insbesondere für Patientinnen mit eingeschränkter Leberfunktion scheint dieses Regime eine hilfreiche Option darzustellen.

\section{KARGER}

Fax +497614520714

Information@Karger.de

www.karger.com (c) 2008 S. Karger GmbH, Freiburg

Accessible online at:

www.karger.com/brc 


\section{Introduction}

The occurrence of liver metastases represents a particular challenge for the systemic therapy of patients with metastatic breast cancer (MBC) [1-3]. Although long-term survival can be achieved in some patients with limited hepatic disease [4], the prognosis for patients with disseminated liver metastases is commonly poor, and a median survival of 14 months after initial diagnosis of liver metastases can be expected [5, 6]. Advanced liver metastases can cause hepatic dysfunction which is clinically apparent by hepatomegaly, jaundice, or the formation of ascites due to cholestasis and/or portal hypertension [7-9].

In general, liver metastases from breast cancer respond to chemotherapy [10], and anthracyclines and taxanes are still the most effective drugs for first-line treatment [11-12]. However, the efficacy of chemotherapy is frequently suboptimal as compared to other metastatic sites, as drug activity can be affected by impaired metabolic liver function [1]. Furthermore, hepatic dysfunction often limits the therapeutic options in these patients due to insufficient biliary drug clearing $[8,9]$, and severe toxicity has been reported after administering standard dose regimens [13-15]. In particular, persisting hyperbilirubinemia with serum levels $>2 \mathrm{mg} / \mathrm{dl}$ precludes the use of most cytotoxic drugs $[16,17]$. In contrast to this, reports have also been published indicating that metastasis-induced hepatic dysfunction normalized after careful, effective cytotoxic treatment [18-21].

Mitomycin $\mathrm{C}(\mathrm{MMC})$ is active in the treatment of many solid tumors including breast cancer, with response rates of about $15-20 \%$ in pretreated breast cancer patients [22, 23]. Because of its unique efficacy in hypoxic tumor areas, MMC represents an interesting combination drug [24]. This is of particular interest in the treatment of patients suffering from hepatic metastases, as hypoxic areas have been found in the core of secondary liver tumors [25]. Therefore, MMC has been used as single-agent therapy in studies evaluating isolated hyperthermic liver perfusion in patients with advanced liver metastases [26]. The antimetabolite 5-fluorouracil (5-FU) is widely used in the adjuvant and palliative treatment of patients with breast cancer and can be combined with more myelotoxic drugs due to its moderate bone marrow toxicity [27, 28]. Furthermore, 5FU combined with folinic acid has proven to be more active than 5-FU alone in treating many chemoresistant tumors, and is considered the 'gold standard' in the therapy of colorectal cancers [29-31]. Finally, capecitabine, an oral fluoropyrimidine that mimics continuous infusion of 5-FU, has also shown signs of being active in MBC patients with advanced liver metastases [20, 21]. Combination chemotherapies consisting of MMC and 5-FU have been shown to be effective in the palliative treatment of patients with advanced gastric or colorectal cancer [32-35]. In addition, MMC and 5-FU are active antineoplastic drugs that can be combined for the palliative therapy of MBC, even after intensive pretreatment [36-38]. More-
Table 1. Main patient characteristics $(n=44)$

\begin{tabular}{|c|c|}
\hline \multirow[t]{2}{*}{ Age, years, median (range) } & $59(24-76)$ \\
\hline & $\begin{array}{l}\text { Patients, } \mathrm{n} \text {, } \\
\text { median }\end{array}$ \\
\hline \multicolumn{2}{|l|}{ Menopausal status } \\
\hline Premenopausal & 3 \\
\hline Postmenopausal & 41 \\
\hline \multicolumn{2}{|l|}{ Histology of primary tumor } \\
\hline Invasive ductal carcinoma & 40 \\
\hline Invasive lobular carcinoma & 3 \\
\hline Other & 1 \\
\hline \multicolumn{2}{|l|}{ Grading } \\
\hline G I & 0 \\
\hline G II & 18 \\
\hline G III & 22 \\
\hline Data missing & 4 \\
\hline \multicolumn{2}{|l|}{ Hormonal receptor status } \\
\hline ER/PR-positive & 32 \\
\hline ER/PR-negative & 9 \\
\hline Data missing & 3 \\
\hline \multicolumn{2}{|l|}{ Different metastatic sites, $\mathrm{n}$} \\
\hline 1 & 13 \\
\hline 2 & 20 \\
\hline 3 & 11 \\
\hline \multicolumn{2}{|c|}{ WHO performance before start of MiFoFU } \\
\hline 0 & 22 \\
\hline 1 & 20 \\
\hline$\geq 2$ & 2 \\
\hline \multicolumn{2}{|c|}{ Chemotherapy regimens in palliative setting, $n$} \\
\hline 0 & 11 \\
\hline 1 & 25 \\
\hline$\geq 2$ & 8 \\
\hline \multicolumn{2}{|c|}{ Administered chemotherapy cycles, $\mathrm{n}$} \\
\hline Total & 239 \\
\hline Per patient, median (range) & $6(3-10)$ \\
\hline
\end{tabular}

$\mathrm{ER}=$ Estrogen receptor $\mathrm{PR}=$ progesterone receptor; $\mathrm{MiFoFU}=$ mitomycin $\mathrm{C} /$ folinate/5-fluorouracil.

over, a combination chemotherapy consisting of MMC, folinic acid, and 5-FU (MiFoFU) has been shown to be active and safe in the treatment of patients with advanced liver metastases secondary to breast cancer and hepatic dysfunction [39]. The aim of this retrospective analysis was to study the activity and tolerability of MiFoFU combination chemotherapy in a larger cohort of patients with liver metastases from breast cancer. In particular, patients in whom liver dysfunction was clinically apparent were studied.

\section{Patients and Methods}

\section{Study Design and Patients}

The charts of all patients with MBC who received MiFoFU combination chemotherapy at the University of Heidelberg Medical School, Department of Gynecology and Obstetrics, between 1998 and 2003 were studied. Patients had to be women, aged 18 years or over, with an ECOG performance status of $0-3$. Liver metastases had to have been proven by clinical findings and imaging studies (ultrasound and/or computed tomogra- 
Table 2. Response rates and survival data (entire study population, $\mathrm{n}=$ 44)

\begin{tabular}{lc}
\hline Complete remission, $\mathrm{n}(\%)$ & $2(5)$ \\
Partial remission, $\mathrm{n}(\%)$ & $4(9)$ \\
Stable disease, $\mathrm{n}(\%)$ & $23(52)$ \\
Clinical benefit rate ${ }^{\mathrm{a}}, \mathrm{n}(\%)$ & $28(64)$ \\
Progressive disease, $\mathrm{n}(\%)$ & $15(34)$ \\
Median time to progression, months & 9 (range 2-40) \\
Median overall survival, months & 14 (range 1.5-91) \\
\hline
\end{tabular}

${ }^{\mathrm{a} C o m p l e t e}+$ partial response + stable disease $\geq 6$ months.

Table 3. Non-hematological toxicity

\begin{tabular}{lclll}
\hline Toxicity & $\begin{array}{l}\text { Grade I, } \\
\mathrm{n}(\%)\end{array}$ & $\begin{array}{l}\text { Grade II, } \\
\mathrm{n}(\%)\end{array}$ & $\begin{array}{l}\text { Grade III, } \\
\mathrm{n}(\%)\end{array}$ & $\begin{array}{l}\text { Grade IV, } \\
\mathrm{n}(\%)\end{array}$ \\
\hline $\begin{array}{l}\text { Non-hematological } \\
\quad \text { Stomatitis }\end{array}$ & $10(23.8)$ & $0(0)$ & $0(0)$ & $1(2.3)$ \\
$\quad \begin{array}{l}\text { Nausea/vomiting } \\
\text { Diarrhea }\end{array}$ & $10(23.8)$ & $1(2.4)$ & $1(2.4)$ & $0(0)$ \\
Hematological & $17(40.5)$ & $0(0)$ & $0(0)$ & $0(0)$ \\
$\begin{array}{l}\text { Anemia } \\
\text { Leukopenia }\end{array}$ & $16(38.1)$ & $16(38.1)$ & $1(2.4)$ & $0(0)$ \\
Thrombocytopenia & $8(19.5)$ & $9(22)$ & $5(12.2)$ & $1(2.44)$ \\
& $8(19)$ & $6(14.3)$ & $5(11.9)$ & $0(0)$ \\
\hline
\end{tabular}

phy/magnetic resonance imaging). All analyses were performed according to the Declaration of Helsinki.

\section{Treatment Schedule}

All patients received a 4-week treatment schedule of MMC $\left(8 \mathrm{mg} / \mathrm{m}^{2}, 15-\right.$ min intravenous (i.v.) infusion) on day 1 , and folinic acid (500 $\mathrm{mg}$ total dose, i.v. bolus) plus 5 -FU (750 mg/m², 2-h i.v. infusion) on days 1 and 2 . Prednisone $50 \mathrm{mg}$ was administered orally from day 1 to 5 to prevent pulmonary toxicity. Dexamethasone $8 \mathrm{mg}$ i.v., ondansetron $8 \mathrm{mg}$ i.v., and ranitidine $50 \mathrm{mg}$ i.v. were added on days 1 and 2 to prevent nausea and gastrointestinal toxicity. Toxicity was assessed before each treatment cycle according to the National Cancer Institute Common Toxicity Criteria (NCI-CTC) version 2.0. Cellular blood cell counts were taken weekly, or more often if clinically indicated. Blood chemistry values were checked before each treatment cycle.

\section{Study Endpoints}

Primary endpoints were response rate and time to progression (TTP); secondary endpoints were overall survival (OS) and tolerability. Complete remission (CR) was defined as complete disappearance of all clinical, radiographic, and biochemical evidence of disease. Partial remission (PR) meant a $50 \%$ or greater reduction of the sum of the product of the longest diameter and its perpendicular of all measurable lesions. Progressive disease (PD) was defined as the appearance of new lesions, significant increase in tumor markers $(>50 \%)$, or radiographic increase of $\geq 25 \%$ in the sum of the products of the longest diameter and its perpendicular, as compared with the lowest value recorded. Patients without $\mathrm{CR}, \mathrm{PR}$, or PD were considered as having stable disease (SD). The clinical benefit rate (CBR) was determined as rate of patients with either CR or PR or with SD for more than 6 months. TTP was calculated from the start of treatment until progression occurred. OS was determined as the time interval between commencement of therapy and death of the patient or date of the last observation. Toxicity and tolerability analyses were per-
Table 4. Characteristics of patients with clinical signs of reduced or impaired liver function $(\mathrm{n}=16)$

\begin{tabular}{lc}
\hline Age, years, median (range) & 61 (40-76) \\
\cline { 2 - 2 } & $\begin{array}{c}\text { Patients, } \mathrm{n}, \\
\text { median (range) }\end{array}$ \\
\cline { 2 - 2 } & \\
WHO performance status before start of \\
MiFoFU \\
0
\end{tabular}

formed in all patients who completed at least 1 cycle of therapy. Hematological and non-hematological toxicities were evaluated and graded according to the NCI-CTC.

\section{Results}

\section{Patient Characteristics}

In all, 44 patients were eligible for retrospective analysis. Median age was 59 years (range 24-76). In 13 patients, the liver was the only proven site of metastasis; 11 patients suffered from metastatic disease involving 3 or more different sites. In terms of pretreatment, 33 patients had already received at least 1 palliative chemotherapy regimen, and 11 patients had been treated with MiFoFU as first-line therapy for MBC. Including adjuvant therapies, a total of 35 patients (81\%) had received anthracycline pretreatment upon entry in the study, 11 patients $(25 \%)$ had previously received taxanes, and 9 patients were refractory to treatment with anthracyclines and taxanes $(20 \%)$. The median number of chemotherapy cycles administered per patient was 6 (range 3-10), with a total number of 239 cycles. At the time of the analysis, 44 patients had died as a result of disease progression. Table 1 provides further details about the main patient characteristics. 
Table 5. Subgroup analysis: activity and tolerability in patients with hepatic dysfunction

Fig. 1. Kaplan-Meier analysis of time to progression (TTP; months), stratified according to presence or absence of signs of liver dysfunction $(\mathrm{p}<0.05)$.

Fig. 2. Kaplan-Meier analysis of overall survival (OS; months), stratified according to presence or absence of signs of liver dysfunction $(\mathrm{p}=0.08)$.

\begin{tabular}{lc}
\hline Survival data, months, median (range) \\
Time to progression & 6.5 \\
Overall survival & 8.6 \\
\cline { 2 - 2 } & Patients, $\mathrm{n}$, \\
& median (range) \\
\cline { 2 - 2 } Response & \\
Complete remission & $0(0)$ \\
Partial remission & $1(6)$ \\
No change & $7(44)$ \\
Clinical benefit rate & \\
Progressive disease & $8(50)$ \\
Non-hematological toxicity & $8(50)$ \\
Stomatitis (grade III/IV) & $0(0)$ \\
Nausea/vomiting (grade III/IV) & $0(0)$ \\
Diarrhea (grade III/IV) & $0(0)$ \\
Hematological toxicity & \\
Anemia (grade III/IV) & $0(0)$ \\
Leukopenia (grade III/IV) & $2(13)$ \\
Thrombocytopenia & $6(38)$ \\
$\quad$ (grade III/IV) & \\
\hline
\end{tabular}

${ }^{\mathrm{a}}$ Complete + partial response + stable disease $\geq$ 6 months.
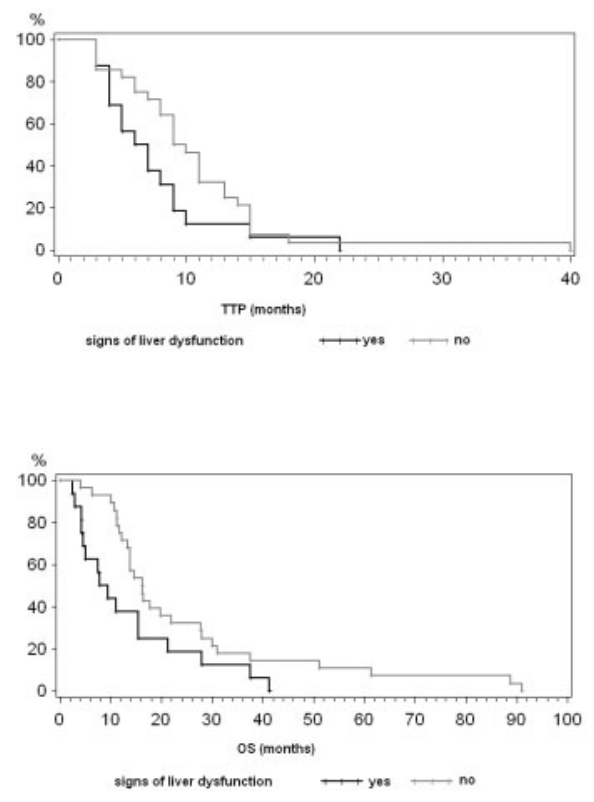

\section{Discussion}

The treatment of liver metastases from breast cancer represents a particular challenge in the management of MBC patients. Hepatic metastases can cause liver dysfunction associated with increased toxicity and limited antineoplastic activity of the administered chemotherapeutics. Although anthracyclines and taxanes are still the preferred drugs for first-line treatment [10-12], we demonstrated that the MiFoFU combination chemotherapy regimen consisting of MMC, folinic acid, and 5-FU represents an active salvage therapy in patients with predominant liver metastases. The clinical benefit rate of $64 \%$ was satisfactory even in patients who had previously received 
anthracycline and taxane pretreatment. MiFoFU could be managed well in an outpatient setting. Only 6 patients $(14 \%)$ discontinued the treatment due to adverse events. Furthermore, with the 4-week schedule, patients only need to visit the hospital twice a month. Finally, this regimen can be administered at relatively low costs.

Liver metastases may cause hyperbilirubinemia either as a result of obstructive cholestasis [9] or disseminated intrahepatic spread and damage to the liver parenchyma [40]. Most cytotoxic drugs cannot be delivered at standard dosages under these circumstances [16,17], and severe toxicity has been observed [13-15]. Nevertheless, promising reports have been published on the successful treatment of MBC patients with advanced liver metastases and associated normalization of an initially reduced liver function [18-21]. Accordingly, it is important to search for alternative strategies for treating patients with hepatic dysfunction, i.e. hyperbilirubinemia, due to breast cancer liver metastases. We previously reported on the management of such a patient who presented with hyperbilirubinemia of $20 \mathrm{mg} / \mathrm{dl}$ and was successfully treated after endoscopic stenting of the common bile duct and subsequent salvage chemotherapy with MiFoFU in increasing doses [9]. Moreover, Loibl et al. [39] recently showed that a combined MiFoFU chemotherapy was feasible and active in a series of $30 \mathrm{MBC}$ patients with hepatic dysfunction due to advanced liver metastases [39]. Our results are in line with these data, although our survival data were slightly better for a comparable subgroup. This might be explained by the fact that only 5 patients with hyperbilirubinemia were included in our study, whereas Loibl et al. [39] reported on 18 such patients.

Toxicity was generally acceptable, mainly as hematotoxicity.
We observed grade III/IV thrombocytopenia and leukopenia in $20 \%$ of all studied patients. Patients with hepatic dysfunction presented more often with grade III/IV thrombocytopenia (38 vs. $12 \%$ in all), whereas all other toxicity remained similar. Thus, a careful monitoring of the cellular blood cell count provided, these data suggest that salvage therapy with MiFoFU is equally feasible, independent of adequate hepatic clearing function.

The question whether to use a single agent or combination therapies in patients with $\mathrm{MBC}$, is still not answered and should be decided on an individual basis [41,42]. As we previously reported, MiFoFU combination chemotherapy appears to be ideal in clinical settings where faster remission is needed and the risk of major toxicities should be avoided [38]. This is frequently the case in patients with breast cancer-derived liver metastases. Thus, MiFoFU can be considered as an alternative beside monotherapies, mainly used in settings without urgent need for remission, and more toxic combination therapies, preferred for symptomatic patients in whom a fast symptom relief is needed.

In summary, MiFoFU combination therapy appears to be a reasonable and well tolerated alternative as salvage treatment for patients with liver metastases from breast cancer. This regimen is also active and feasible in patients showing clinical signs of reduced or impaired hepatic function. As our study is limited by its retrospective attempt, future clinical trials with a prospective design are warranted to confirm this hypothesis, especially for patients with hepatic dysfunction. This strategy may offer an important option for MBC patients with weak performance and in whom treatment is limited due to hepatic metastases.

\section{References}

1 Zinser JW, Hortobagyi GN, Buzdar AU, Smith TL, Fraschini G: Clinical course of breast cancer patients with liver metastases. J Clin Oncol 1987;5 773-82.

2 Hoe AL, Royle GT, Taylor I: Breast liver metastases - incidence, diagnosis and outcome. J R Soc Med 1991;84:714-6.

3 Pritchard KI: Liver Metastases: can our understanding of their biology and prognostic value contribute to a strategy for optimum therapeutic management? Eur J Canc 1997;33(suppl 7):S11-4.

4 Eichbaum M, Kaltwasser M, Bruckner T, Schneeweiss A, Bastert G: Characteristics of patients with long-term survival after occurrence of liver metastases from breast cancer. Eur J Cancer 2003;1(suppl): S136.

$\checkmark 5$ Wyld L, Gutteridge E, Pinder SE, James JJ, Chan SY, Cheung KL, Robertson JF, Evans AJ: Prognostic factors for patients with hepatic metatases from breast cancer. Brit J Cancer 2003;89:284-90.

$\checkmark 6$ Eichbaum M, Kaltwasser M, Bruckner T, Schneeweiss A, Sohn C: Prognostic factors for patients with liver metastases from breast cancer. Breast Cancer Res Treat 2006;96:53-62.

7 Agarwal K, Jones DE, Burt AD, Hudson M, James OF: Metastatic breast carcinoma presenting as acute liver failure and portal hypertension. Am J Gastroenterol 2002;97:750-1.
8 Robieux I, Sorio R, Borsatti E, Cannizzaro R, Vitali V, Aita P, Freschi A, Galligioni E, Mofardini S: Pharmacokinetics of vinorelbine in patients with liver metastases. Clin Pharmacol Ther 1996;59: $32-40$.

9 Eichbaum M, Schneeweiss A, de Rossi T, Bastert G: Endoscopic stenting of the common bile duct allows successful treatment of a breast cancer patient with excessive liver metastases. Am J Clin Oncol 2004;27:642-3.

10 Piccart MJ, Bernard-Marty C, Cardoso F: Non-endocrine systemic therapies in advanced breast cancer. Eur J Cancer 2003;1(suppl):S287-98.

11 Chan S, Friedrich K, Noel D; for the study 303 group: Prospective randomised trial of docetaxel versus doxorubicin in patients with metastatic breast cancer. J Clin Oncol 1999;17:2351-4.

12 Atalay G, Biganzoli L, Renard F, Paridaens R, Cufer T, Coleman R, Calvert AH, Gamucci T, Minisini A, Therasse P. Piccart MJ: Clinical outcome of breast cancer patients with liver metastases alone in the anthracycline-taxane era: a retrospective analysis of two prospective, randomised metastatic breast cancer trials. Eur J Cancer 2003;39:2439-49.

13 Feenstra J, Vermeer RL, Stricker BH: Fatal hepatic coma attributed to paclitaxel. J Natl Cancer Inst 1997;89:582-4.
14 Tomassini E, Muhizi J, al Raheb K, Steinbach G, Bemer M, Platini C: Fulminant hepatocellular necrosis following administration of docetaxel. Presse Med 2001;97:750-1.

15 Robinson K, Lambiase L, Li J, Monteiro C, Schiff M: Fatal cholestatic liver failure associated with gemcitabine therapy. Dig Dis Sci 2003;48:1804-8.

16 Johnson PJ, Dobbs N, Kalayci C, Aldous MC, Harper P, Metivier EM, Williams R: Clinical efficacy and toxicity of standard dose adriamycin in hyperbilirubinemic patients with hepatocellular carcinoma: relation to liver tests and pharmacokinetic parameters. Br J Cancer 1992;65:751-5.

17 Mano MS, Cassidy J, Canney P: Liver metastases from breast cancer: management of patients with significant liver dysfunction. Cancer Treat Rev 2005;31:35-48.

18 Gurevich I, Akerley W: Treatment of the jaundiced patient with breast carcinoma. Cancer 2001;91: 660-3.

19 Sharma RA, Decatris MP, Santhanam S, Roy R, Osman AE, Clarke CB, Khanna S, O'Byrne KI: Reversibility of liver failure secondary to metastatic breast cancer by vinorelbine and cisplatin chemotherapy. Cancer Chemother Pharmacol 2003;52: 367-70. 
20 Schull B, Schiethauer W, Kornek GV: Capecitabine as salvage therapy for a breast cancer patient with extensive liver metastases and associated impairment of liver function. Onkologie 2003;26:578-80.

21 Henry S, Manchiels J-P, Baurain J-F, Druck L: Liver insufficiency due to breast cancer metastases. Acta Oncol 2004;43:302.

22 Garewal HS: Mitomycin C in the chemotherapy of advanced breast cancer. Semin Oncol 1988;15: 74-79.

23 Bradner WT: Mitomycin C: a clinical update. Cancer Treat Rev 2001;27:35-50.

24 Kennedy KA, Rockwell S, Sartorelli AC: Preferential activation of mitomycin $\mathrm{C}$ to cytotoxic metabolites by hypoxic tumor cells. Cancer Res 1980;40: 2356-60.

25 Van Laarhoven HW, Kaanders JH, LOK J, Peeters WJ, Rijken PF, Wiering B, Ruers TJ, Punt CJ, Heerschap A, van der Kogel AJ: Hypoxia in relation to vasculature and proliferation in liver metastases in patients with colorectal cancer. Int J Radiat Oncol Biol Phys 2006;64:473-82.

26 Oldhafer KJ, Freker MK, Lang H, Fauler J, Flemming P, Schmoll E, Nadalin S, Moreno L, Pichlmayr $\mathrm{R}$ : High-dose mitomycin $\mathrm{C}$ in isolated hyperthermic liver perfusion for unresectable liver metastases. J Invest Surg 1998;11:393-400.

-27 Doroshow JH, Leong L, Margolin K, Flanagan B, Goldberg D, Bertrand M, Akman S, Carr B, Odujinrin O, Litchfield T: Effective salvage therapy for refractory disseminated breast cancer with fluorouracil and high-dose continuous infusion folinic acid. Adv Exp Med Biol 1988;244:245-53.

28 Wilke H, Klaassen U, Achterrath W, Losch M, Vanhoefer U, Hayungs J, Harstrick A, Stahl M, Eberhardt W, Becher M, Seeber S: Phase I/II study with a weekly 24-hour infusion of 5-fluorouracil plus high-dose folinic acid (HD-FU/FA) in intensively pretreated patients with metastatic breast cancer. Ann Oncol 1996;7:55-8.
29 Petrelli NJ, Rustum YM, Bruckner, Stablein D: The Roswell Park Memorial Institute and Gastrointestinal Tumor Study Group phase III experience with the modulation of 5-fluorouracil by leucovorin in metastatic colorectal adenocarcinoma. Adv Exp Med Biol 1988;244:143-55.

30 Petrioli R, Lorenzi M, Aquino A, Marsili S, Frediani B, Palazzuoli V, Marzocca G, Botta G, Tani F, De Martino A: Treatment of advanced colorectal cancer with high-dose intensity folinic acid and 5fluorouracil plus supportive care. Eur J Cancer 1995;31A:2105-8.

31 Schmiegel W, Pox C, Adler G, Fleig W, Folsch UR, Fruhmorgen P, Graeven U, Hohenberger W, Holstege A, Kuhlbacher T, Porschen R, Propping P, Riemann JF, Sauer R, Sauerbruch T, Schmoll HJ, Zeitz M, Selbmann: S3-Leitlinienkonferenz 'Kolorektales Karzinom' 2004. Dtsch Med Wochenschr 2005;130(suppl 1):S5-53.

32 Becker K, Rinas U, Gauler T, Widmann B, Heider A, Niederle N: High-dose 5-fluorouracil/ folinic acid (HD-5-FU/FA) plus mitomycin C (MMC) in patients with refractory colorectal cancer. J Cancer Res Clin Oncol 1998;124(suppl):R162.

33 Hofheinz RD, Hartung G, Samel S, Hochhaus A, Pichlmeier U, Post S, Hehlmann R, Queisser W: High-dose 5-fluorouracil/ folinic acid in combination with three-weekly mitomycin $\mathrm{C}$ in the treatment of advanced gastric cancer. A phase II study. Onkologie 2002;25:225-60.

34 Hartmann JT, Oechsle K, Quietzsch D, Wein A, Hofheinz RD, Honecker F, Nehls O, Kohne CH, Kafer G, Kanz L, Bokemeyer C: Protracted infusional 5-fluorouracil plus high-dose folinic acid combined with bolus mitomycin $\mathrm{C}$ in patients with gastrointestinal cancer: a phase I/II dose escalation study. Brit J Cancer 2003;89:2051-6.
5 Rudi J, Werle S, Bergtholdt D, Hofheinz RD: Infusional 5-fluorouracil and mitomycin C: an effective regimen in the treatment of advanced gastric cancer. Onkologie 2005;28:128-32.

36 Francini G, Petrioli R, Messinese S, Pozzessere D, Marsili S, Correale P, Sabatino M, Fiaschi AI Folinic acid, 5-fluorouracil and mitomycin $\mathrm{C}$ in metastatic breast cancer patients previously treated with at least two chemotherapy regimens. Cancer Chemother Pharmacol 2002;50:271-6.

37 Tauchert S, Maltaris T, Ertan K, Diedrich K, Schmitt W, Friedrich M: Infusionstherapie mit hochdosiertem 5-FU/Natriumfolinat in Kombination mit Mitomycin C (MMC): eine Dosiseskalations-Studie (Phase I) bei Patientinnen mit metastasiertem Mammakarzinom. Senologie 2005;2:193.

38 Eichbaum M, Gast AS, Schneeweiss A, Bruckner T, Sohn C: Activity and tolerability of a combined chemotherapy with mitomycin $\mathrm{C}$, folinate, and 5fluorouracil in patients with advanced metastatic breast cancer after intensive pretreatment - a retrospective analysis. Am J Clin Oncol 2007;30:139-45.

39 Loibl S, von Minckwitz G, Schwedler K, Schmidt KA, Hoper D, Kaufmann M, Costa S: Mitomycin C, 5-fluorouracil and folinic acid (Mi-Fu-Fo) as salvage chemotherapy in breast cancer patients with liver metastases and impaired hepatic function: a phase II study. Anticancer Drugs 2004; 15:719-24.

40 Martelli O, Coppola L, De Quarto AL, Plama M, Sarmiento R, Foggi CM: Fulminant hepatic failure caused by diffuse intrasinusoidal metastatic liver disease: a case report. Tumori 2000;86:424-7.

41 Seldman AD: Monotherapy options in the management of metastatic breast cancer. Semin Oncol 30 (suppl 3):6-10.

42 Reichardt P, Miles D: Setting the record straight: activity of gemcitabine monotherapy for breast cancer. Oncology 2004;66:339-40. 